\title{
Introduction to the special issue of unconventional hydrocarbon research
}

\author{
Yan Song ${ }^{1,2}$
}

Received: 11 May 2015/Published online: 29 September 2015

(c) The Author(s) 2015. This article is published with open access at Springerlink.com

Unconventional hydrocarbon research has developed rapidly in the recent years. In order to review the advances in unconventional hydrocarbon research in the areas of reservoir geology, geophysics, engineering, and economic evaluation, the Unconventional Natural Gas Institute (UNGI) of China University of Petroleum (Beijing) was invited to organize this special issue. Papers in this special issue are mainly about tight oil and gas, shale oil and gas, and coalbed methane, which are the main types of unconventional hydrocarbon.

In the area of geology and accumulation mechanisms, Song et al. divided unconventional oil and gas into different types based on relationships between source rock evolution and different unconventional reservoirs and further noted that the fundamental difference between unconventional and conventional hydrocarbons is the driving force. Xiao et al. discussed the controlling factors and enrichment area evaluation of shale gas of the Lower Paleozoic marine strata in south China, and established geological and loss models of shale gas for uplifted/folded and faulted/folded areas. Jiang et al. identified three types of tight sandstone gas reservoirs according to the timing of coupling between the two phases of gas charging and reservoir tightening, and clarified the controlling factors, accumulation mechanisms and modes of different types of

Yan Song

sya@petrochina.com.cn

1 State Key Laboratory of Petroleum Resources and Prospecting, China University of Petroleum, Beijing 102249, China

2 Unconventional Natural Gas Institute, China University of Petroleum, Beijing 102249, China

Edited by Jie Hao tight gas reservoirs. Zou et al. optimized the evaluation parameters and standards of the tight oil "sweet spots" which are significant for the exploration of tight oil in China.

In the area of geophysical exploration, Yin et al. proposed a constrained basis pursuit inversion (BPI) method for stably estimating the Young's modulus and Poisson's ratio, and effectively predicting the brittleness of unconventional reservoirs.

In the area of hydraulic fracturing, Zeng et al. used the finite element method to quantify the stress distribution and investigated the controlling mechanism of the stress distribution of multi-stage hydraulic fracturing and fracture expansion. Ge et al. discussed the interaction between hydraulic fracturing fluids and shale matrix, clarified the mechanism of low flowback efficiency of fracturing fluids, and established its relationship to gas productivity.

In the area of development and economic evaluation, $\mathrm{Hu}$ et al. discussed the pore structure of typical American and Chinese shales and investigated the effect of pore structure on the decline of shale gas well production. Wang et al. discussed the influence of gas transport mechanisms on the productivity of multi-stage fractured horizontal wells in shale gas reservoirs. Zhang et al. proposed a model of hydraulic fracture in tight oil reservoirs by using a combined finite and discrete element method to direct the hydraulic fracturing of tight reservoirs. Tang et al. quantitatively divided the coalbed methane well-production process into four stages and quantitatively characterized the coal reservoir permeability change in different stages. Zhang et al. simulated the absolute adsorption and excess adsorption capacity of medium rank coal to $\mathrm{CO}_{2}, \mathrm{CH}_{4}$, and $\mathrm{C}_{2} \mathrm{H}_{6}$ gas using molecular dynamics, and provided a theoretical support for improving coalbed methane recovery using $\mathrm{CO}_{2}$ injection. Luo et al. applied the discounted cash 
flow method to building an economic evaluation model, which reduced investment waste and improved the quality of decision-making in exploration target selection. Chen et al. proposed a new method for economic evaluation of shale gas, which has great application value.

In summary, this special issue brings together some of the latest achievements of unconventional oil and gas exploration and development research at home and abroad.

The UNGI of China University of Petroleum (Beijing) was established in 2011 when the world's energy configuration is undergoing major changes with the rapid development of unconventional oil and gas resources.

UNGI focuses on the basic theory and technology development research of tight gas, shale gas, and coalbed methane. Its key technology research and development areas include accumulation theory and geological evaluation of unconventional natural gas reservoirs, rock mechanics and formation evaluation, geophysical exploration for unconventional natural gas, fracturing treatment of unconventional reservoirs, percolation mechanisms, and simulation of unconventional gas reservoirs. UNGI has formed an influential multi-disciplinary unconventional oil and gas research team. It has made important advances in multi-scale pore structure characterization of tight reservoirs, evolution of free and adsorbed gas in shale gas reservoirs, new fracture imaging methods, and in understanding mechanisms of the damage to tight reservoirs by fracturing fluids. Areas such as geological assessment, geophysical exploration, reservoir drilling and completion, mechanisms of development and economic evaluation of unconventional oil and gas have seen remarkable progress.

About the Guest Editor-in-chief of this special issue Professor Yan Song is Dean of the Unconventional Natural Gas Institute of China University of Petroleum (Beijing) and Associate Director of the State Key Laboratory of Petroleum Resources and Prospecting. She is the chief scientist of two coalbed methane projects of the Major State Basic Research Development Program of China (973 Program) and subject matter expert in resource and environment fields of the National High Technology Research and Development Program of China (863 Program). Prof Song has also been principal organizer and project leader of the Natural Gas National Key Technologies Research and Development Program of China during the 8th, 9th, 10th Five-Year Plan Periods and of the National Science and Technology Major Project during the 11th Five-Year Plan Period. Professor Song's work has been dedicated to natural gas geology and oil and gas accumulation research for many years. She has obtained important results in geological theories of coalbed methane accumulation, conventional natural gas accumulation, and oil and gas accumulation in foreland basins, and has published more than 170 papers and 13 monographs.

Open Access This article is distributed under the terms of the Creative Commons Attribution 4.0 International License (http://crea tivecommons.org/licenses/by/4.0/), which permits unrestricted use, distribution, and reproduction in any medium, provided you give appropriate credit to the original author(s) and the source, provide a link to the Creative Commons license, and indicate if changes were made. 